\title{
Chloroquine and Hydroxychloroquine: Are they Really Wonder Drugs for COVID 19?
}

\author{
Mohammad Abu Bashar* \\ MM Institute of Medical Sciences \& Research, MM Deemed University, Mullana, Haryana, India \\ *Corresponding author: Mohammad Abu Bashar, MM Institute of Medical Sciences \& Research, MM Deemed University, \\ Mullana, Haryana, India
}

\section{ARTICLE INFO}

Received: 幽 July 04, 2020

Published: 㗀 July 13, 2020

Citation: Mohammad Abu Bashar. Chloroquine and Hydroxychloroquine: Are they Really Wonder Drugs for COVID 19?. Biomed J Sci \& Tech Res 28(5)-2020. BJSTR. MS.ID.004711.

Abbreviations: FDA: Food and Drug Administration; SARS-CoV-2: Severe Acute Respiratory Coronavirus-2; CQ: Chloroquine; HCQ: Hydroxychloroquine; ICMR: Indian Council for Medical Research; DCGI: Drug Controller General of India; AZM: Azithromycin

\section{ABSTRACT}

Despite limited and conflicting data on the use of Chloroquine and hydroxychloroquine in patients with Covid-19, the U.S. Food and Drug Administration (FDA) authorized the emergency use of these drugs on March 28, 2020 given the clinical trials were unavailable or infeasible. Hydroxychloroquine, alone or in combination with azithromycin, is being widely used in Covid-19 therapy and/prophylaxis around the globe based on anecdotal and limited observational evidence.

\section{Summary}

Chloroquine \& hydroxychloroquine were approved as a treatment option and prophylaxis for COVID-19 by US FDA \& Indian Council for Medical research respectively in emergency situations. Data till date, however, does not support the use of these drugs for either of these indications. Results of large placebo controlled trials, some of which are ongoing, are required to come to use these drugs on wide scale either for treatment or for post exposure prophylaxis. Given the grave safety concerns particularly in severely ill patients, the use of these drugs, currently, should only be limited for trial purpose.

\section{Mini Review}

Since the first case being reported in December 2019 from Wuhan, China, infection with the severe acute respiratory coronavirus 2 (SARS-CoV-2) i.e. COVID 19, has become a worldwide pandemic [1,2]. The pandemic has also challenged the slow and highly regulated drug-approval process across the globe [3]. On March 28, 2020, the U.S. Food \& Drug Authority(FDA), the highest drug approving agency across the world, authorized use of the antimalarial drugs chloroquine (CQ) and hydroxychloroquine (HCQ) to treat COVID-19 patients without any clinical trial data and despite inconclusive clinical evidence of effectiveness [4]. Before that, on 22 march, 2020, National task force for COVID-19 constituted by Indian Council for Medical research (ICMR) recommended the use of hydroxyl-chloroquine for prophylaxis of SARS-Cov-2 infection in high risk individuals [5]. The recommendation was approved by Drug controller general of India(DCGI) for restricted use in emergency situations. Interest in these drugs was generated by the conviction that most COVID-19 patients are probably in an antiviral-susceptible stage before clinical presentation.

Following a primary phase marked by the usual respiratory symptoms, fevers, and malaise, patients most affected by COVID-19 develop a severe inflammatory respiratory illness, driven largely by the host immune response. Laboratory data show evidence of massive inflammation, including elevated C-reactive protein, ferritin, and interleukin-6. CQ and HCQ have demonstrated activity in vitro against SARS-CoV, SARS-CoV-2, and other viruses [6-8]. The mechanism is not clearly understood but it involves raising the $\mathrm{pH}$ of cellular endosomes, rendering less efficient the process of viral entry, replication, and infection and interference with glycosylation of cellular receptors for the virus. In addition, these drugs also appear to reduce host cell autophagy [9]. Given these apparent antiviral and immunomodulatory effects, CQ/HCQ seemed promising [10]. Emergency Use Authorization of CQ/HCQ 
by the FDA for COVID-19 occurred primarily after the extensive publicity cause due to a small non-randomized study, of 36 patients with confirmed COVID-19; 22 having upper respiratory tract infections, 8 having lower respiratory tract infections, and 6 having no symptoms [11]. Of these patients, 20 received HCQ (600 mg daily) and 16 did not (control patients).

Among the HCQ patients, 6 also received azithromycin (AZM; $500 \mathrm{mg}$ on day 1, $250 \mathrm{mg}$ on days 2-5) as a bacterial superinfection prophylaxis. Within 6 days, virologic clearance was seen in $70 \%$ of HCQ recipients and in $12.5 \%$ of controls. All patients treated with HCQ+AZM cleared virus compared with $57.1 \%$ who received HCQ alone only [11]. These findings were not convincing, and the effect was purely microbiological and not clinical. Further, the study was not optimally designed and was potentially subject to bias. Notably, in previous epidemics of chikungunya, dengue, and influenza, the apparent in vitro antiviral effects of CQ/HCQ did not translate into clinical benefits [12]. The first randomized study of HCQ in COVID-19 patients from China had only 30 patients from a single centre and did not show any clinical benefit [13]. A second report published on February 15, 2020, indicated that there were better outcomes associated with CQ therapy than in controls in a review of 100 patients, but the full results are yet to be published in a peerreviewed journal [14]. Beyond the considerable doubts about their efficacy, CQ and HCQ are not without toxicity.

Photosensitivity, gastrointestinal side effects, and other toxicities - while rare - may be augmented in severely ill COVID-19 patients. Of particular concern is QT prolongation due to use of these drugs, as myocarditis and cardiomyopathy appear to be relatively common complications in patients with severe COVID-19 $[15,16]$. Highlighting these concerns, in a double-blind, randomized trial in Brazil of two doses of CQ $(600 \mathrm{mg}$ twice daily for 10 days or $450 \mathrm{mg}$ twice daily for 5 days) for hospitalized patients with COVID-19 recently, the higher-dose arm was discontinued per data safety monitoring board for increased mortality [17]. An additional retrospective review of 368 male patients hospitalized with COVID-19 in U.S. veterans medical centres, released as non-peerreviewed preprint on April 21, 2020, raised a similar concern [18]. Although HCQ recipients and non-recipients differed in several baseline characteristics that could have influenced the findings, the risk for death was higher in the HCQ group than in the non-HCQ group (adjusted hazard ratio with HCQ vs. without, 2.6) [18].

\section{Conclusion}

Although new treatment methods and approaches for the management of COVID-19 are required desperately keeping in view the pandemic situation, most of the available information in relation to the use of CQ/HCQ for COVID-19 comes from studies that were either poorly designed or available as only non-peerreviewed preprints. Placebo-controlled trials evaluating the role of CQ/HCQ as post exposure prophylaxis, in outpatient clinics (mild disease), and in hospitalized patients have now been started at some of the places, results of which are awaited. Given the currently available limited efficacy data and the grave concerns regarding safety, we believe that CQ/HCQ should not be used for COVID-19 until controlled clinical trials clearly and effectively demonstrate the benefits outweighing potential harms.

\section{References}

1. Cucinotta D, Vanelli M (2020) WHO declares COVID-19 a pandemic. Acta Biomed 91(1): 157-160.

2. Spinelli A, Pellino G (2020) COVID-19 pandemic: perspectives on an unfolding crisis. Br J Surg 107(7): 785-787.

3. Rome BN, Avorn J (2020) Drug Evaluation during the Covid-19 Pandemic. N Engl J Med 382(24): 2282-2284.

4. Rick Bright (2020) Food and Drug Administration.

5. Advisory on the use of Hydroxychloroquine for SARS- COV-2 Infection. Ministry of health \& family welfare.

6. Wang M, Cao R, Zhang L, Yang X, Liu J, et al. (2020) Remdesivir and chloroquine effectively inhibit the recently emerged novel coronavirus (2019-nCoV) in vitro. Cell Res 30(3): 269-271.

7. Biot C, Daher W, Chavain N, Fandeur T, Khalife J, et al. (2006) Design and synthesis of hydroxyferroquine derivatives with antimalarial and antiviral activities. J Med Chem 49: 2845-2849.

8. Liu J, Cao R, Xu M, Wang X, Zhang H, et al. (2020) Hydroxychloroquine, a less toxic derivative of chloroquine, is effective in inhibiting SARS-CoV-2 infection in vitro. Cell Discov 6: 16.

9. Yan Y, Zou Z, Sun Y, Li X, Xu KF, et al. (2013) Anti-malaria drug chloroquine is highly effective in treating avian influenza A H5N1 virus infection in an animal model. Cell Res 23(2): 300-302.

10. Colson P, Rolain JM, Raoult D (2020) Chloroquine for the 2019 novel coronavirus SARS-CoV-2. Int J Antimicrob Agents 55(3): 105923.

11. Gautret P, Lagier JC, Parola P, Hoang VT, Meddeb L, et al. (2020) Hydroxychloroquine and azithromycin as a treatment of COVID-19: results of an open-label non-randomized clinical trial. Int J Antimicrob Agents 20: 105949.

12. Paton NI, Lee L, Xu Y, Ooi EE, Cheung YB, et al. (2011) Chloroquine for influenza prevention: a randomised, double-blind, placebo-controlled trial. Lancet Infect Dis 11(9): 677-683.

13. Chen J, Liu D, Liu L, Liu P, Xu Q, et al. (2020) A pilot study of hydroxychloroquine in treatment of patients with moderate COVID-19. J Zhejiang Univ (Med Sci) 49(2): 215-219.

14. Gao J, Tian Z, Yang X (2020) Breakthrough: Chloroquine phosphate has shown apparent efficacy in treatment of COVID-19 associated pneumonia in clinical studies. Biosci Trends 14(1): 72-73.

15. Sanders JM, Monogue ML, Jodlowski TZ, Cutrell JB (2020) Pharmacologic Treatments for Coronavirus Disease 2019 (COVID-19): A Review. JAMA.

16. Chorin E, Dai M, Shulman E, Wadhwani L, Bar Cohen R, et al. (2020) The QT interval in patients with COVID-19 treated with hydroxychloroquine and azithromycin. Nat Med 26: 808-809.

17. Borba MGS, Almeida Val FF, Sampaio VS, Alexandre MAA, Melo GC, et al. (2020) Chloroquine diphosphate in two different dosages as adjunctive therapy of hospitalized patients with severe respiratory syndrome in the context of coronavirus (SARS-CoV-2) infection: Preliminary safety results of a randomized, double-blinded, phase IIb clinical trial (CloroCovid-19 Study). medRxiv.

18. Magagnoli J, Narendran S, Pereira F, Cummings T, Hardin JW, et al. (2020) Outcomes of hydroxychloroquine usage in United States veterans hospitalized with Covid-19. MedRxiv. 
ISSN: 2574-1241

DOI: 10.26717/BJSTR.2020.28.004711

Mohammad Abu Bashar. Biomed J Sci \& Tech Res

(C) This work is licensed under Creative

Submission Link: https://biomedres.us/submit-manuscript.php

$\begin{array}{ll}\text { BIOMEDICAL } & \text { Assets of Publishing with us } \\ \text { RESEARCHES } & \text { - Global archiving of articles } \\ \text { - Immediate, unrestricted online access } & \text { - Rigorous Peer Review Process } \\ & \text { - Authors Retain Copyrights } \\ \end{array}$

